Fujiko Kohata

Jahwist und Priesterschrift in Exodus 3-14 

Fujiko Kohata

\section{Jahwist und Priesterschrift in Exodus 3-14}

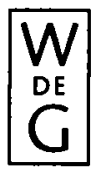

Walter de Gruyter - Berlin - New York

1986 
Beiheft zur Zeitschrift für die alttestamentliche Wissenschaft Herausgegeben von Otto Kaiser

166

gedruckt auf säurefreiem Papier

(alterungsbeständig - $\mathrm{pH} 7$, neutral)

CIP-Kurztitelaufnabme der Deutschen Bibliothek

\section{Kohata, Fujiko:}

Jahwist und Priesterschrift in Exodus 3-14 / Fujiko Kohata. Berlin ; New York : de Gruyter, 1986.

(Beiheft zur Zeitschrift für die alttestamentliche Wissenschaft ;

166)

ISBN 3-11-010649-3

NE: Zeitschrift für die alttestamentliche Wissenschaft / Beiheft

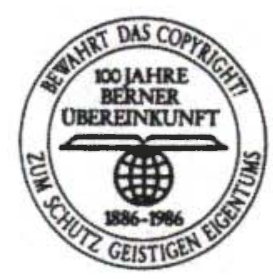

(C) Copyright 1986 by Walter de Gruyter \& Co., Berlin 30.

Printed in Germany - Alle Rechte des Nachdrucks, einschließlich des

Rechts der Herstellung von Photokopien - auch auszugsweise vorbehalten.

Druck: Werner Hildebrand, Berlin 65

Bindearbeiten: Lüderitz \& Bauer, Berlin 61 
Meinen Eltern 
